Quim. Nova, Vol. 35, No. 1, 102-107, 2012

\title{
EFEITO DA ASSOCIAÇÃO DO HERBICIDA CLOMAZONE A NANOESFERAS DE ALGINATO/QUITOSANA NA SORÇÃO EM SOLOS
}

\author{
Mariana dos Santos Silva, Daniela Sgarbi Cocenza, André Henrique Rosa e Leonardo Fernandes Fraceto* \\ Departamento de Engenharia Ambiental, Universidade Estadual Paulista, Av. Três de Março, 511, 18087-180 Sorocaba - SP, Brasil
}

Recebido em 16/2/11; aceito em 7/6/11; publicado na web em 22/7/11

\begin{abstract}
EFFECT OF THE ASSOCIATION OF CLOMAZONE IN ALGINATE/CHITOSAN NANOPARTICLES UNDER SOIL SORPTION. Agrochemicals constitute the class of products most commonly found in water resources. Their high level of concentration is due to the fact that less than $0.1 \%$ of pesticides applied to crops reach their target. The present work aims to study the sorption of clomazone herbicide (associated or not with nanoparticles). The sorption tests, performed with the $2^{4}$ factorial design, showed that the form of herbicide is the main factor for sorption of clomazone. The application of nanoparticles as delivery system for agrochemicals is a pressing area of study and can contribute for decrease in effects of clomazone in the environment.
\end{abstract}

Keywords: clomazone; alginate nanoparticles; soil sorption.

\section{INTRODUÇÃO}

Clomazone, [2-[metil(2-clorofenil)]-4,4-dimetil-3-isoxazolidinona] é um herbicida largamente usado no combate de ervas daninhas de diversas culturas anuais, tais como feijão, algodão, milho, tabaco, arroz, cana-de-açúcar, soja e mandioca. ${ }^{1}$ No solo, dependendo dos níveis de matéria orgânica e tipo de solo, a meia vida do clomazone (Figura 1) pode ser de 28 a 84 dias. $^{2}$ É altamente solúvel em água (1100 mg L a $^{-1} 5^{\circ} \mathrm{C}$ ) e possui valor de Koc (coeficiente de partição carbono orgânico do solo-água) variando entre 150 e $562 \mathrm{~cm}^{3} \mathrm{~g}^{-1}$ e valor de constante da Lei de Henry de $4.19 \times 10^{-3} \mathrm{~Pa} \mathrm{~m}^{3} \mathrm{~mol}^{-1}$, o que lhe confere maior fitotoxicidade quando em presença de água abundante..$^{1,3}$

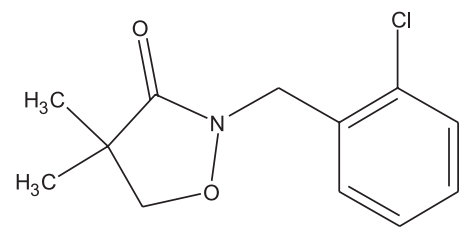

Figura 1. Estrutura química do herbicida clomazone

Estes valores apresentados para o clomazone indicam grande potencial de poluição aquática em ecossistemas. Trata-se de um agente químico muito usado na região sul do Brasil, principalmente em culturas irrigadas de arroz, ${ }^{1}$ onde pode ser encontrado em uma concentração final de $0,7 \mathrm{mg} / \mathrm{L}$. Apesar de ser um herbicida de efeito tóxico menor do que os demais herbicidas usados na cultura de arroz, o resíduo do agrotóxico tem efeito bioacumulativo. ${ }^{2}$

Nos últimos 50 anos o uso de pesticidas aumentou significativamente a produção e a qualidade de alimentos, justificadas pelo crescimento populacional. Estima-se que menos de $0,1 \%$ dos pesticidas aplicados em culturas realmente atinjam o alvo desejado. O restante segue livremente para o solo, águas e ar. Além disso, os agroquímicos permanecem durante anos no meio ambiente e possuem a capacidade de se acumular em tecidos de organismos, alterando as cadeias alimentares.

O comportamento dos herbicidas no solo depende de uma série de parâmetros dinâmicos e complexos físico-químicos, biológicos

\footnotetext{
*e-mail: leonardo@sorocaba.unesp.br
}

incluindo sorção/dessorção, volatilização, degradação química e biológica, absorção por plantas e lixiviação. O processo de adsorção compreende a passagem de um soluto, também chamado adsorbato, da fase aquosa para a superfície de uma substância sólida, denominada adsorvente, prendendo-se a ela por meio de interações físicas ou químicas. O processo reverso, ou seja, à quebra dessas interações e, consequentemente, a liberação do adsorbato, dá-se o nome de dessorção. ${ }^{3}$

Do ponto de vista cinético, a sorção de muitos compostos orgânicos é um processo de duas etapas: uma etapa inicial rápida que é responsável pela grande parte da sorção total seguida por uma etapa mais lenta tendendo ao equilíbrio final. O aumento da sorção de pesticidas no solo com o passar dos anos têm sido observado para uma variedade de classe de pesticidas, usando diferentes métodos. ${ }^{3}$

O mecanismo de sorção tem papel fundamental na dinâmica do transporte advectivo-dispersivo, persistência, transformação e bioacumulação de pesticidas. A sorção de compostos neutros tem sido bastante estudada e parece ser dependente da matéria orgânica contida no solo. A natureza molecular da matéria orgânica do solo tem mostrado ser a chave para determinar a sorção de pesticidas não iônicos. Além disso, estudam-se os processos bióticos e abióticos envolvidos no processo de sorção. Outros constituintes do solo, além da matéria orgânica incluindo argilas e óxidos de ferro, são importantes sorventes de pesticidas iônicos. Muitos estudos têm determinado isotermas de sorção a fim de investigar a influência de parâmetros do solo (matéria orgânica, argila, pH, etc.) na sorção de pesticidas fracamente básicos, ácidos ou neutros por meio de uma ampla variedade de solos. ${ }^{3}$

Há evidências de que produtos químicos aplicados no solo tendem a ser transportados rapidamente para águas subterrâneas. As hipóteses propostas para explicar este transporte incluem fluxo preferencial, cotransporte com materiais coloidais e uma combinação de processos. A taxa e a magnitude do rápido transporte parecem ser influenciadas por diversos parâmetros, dos quais fazem parte não apenas as propriedades do pesticida, bem como as propriedades do solo, suas características hidrológicas e seu manuseio. Para os pesticidas hidrofóbicos, por exemplo, sua mobilidade e risco de lixiviação para águas subterrâneas têm sido relacionados à baixa sorção em matrizes do solo e aos valores quantificados da constante de adsorção à matéria orgânica do solo (Koc). Portanto, pesticidas com altos valores de Koc são encontrados em águas subterrâneas e 
águas de drenagem, presumidamente como resultado de lixiviação a partir de uma combinação de fatores: chuvas rápidas e torrenciais após aplicação de pesticida e presença de caminhos preferenciais, o que acontece mais facilmente nos trópicos. ${ }^{3}$

Os mecanismos que operam os processos de adsorção de pesticidas em substâncias húmicas presentes no solo incluem ligações iônicas, covalentes e de hidrogênio; transferência de carga; forças de van de Waals; troca de ligantes e ligações hidrofóbicas ou de partição. Deve-se lembrar que estes mecanismos não ocorrem todos simultaneamente, porém, dois ou mais provavelmente ocorrem ao mesmo tempo, dependendo da natureza do grupo funcional e das condições do $\mathrm{pH}$ do sistema. ${ }^{4}$

Neste contexto torna-se importante o desenvolvimento de novas tecnologias/formulações capazes de reduzir os efeitos aos organismos não alvos, diminuir o uso de produtos químicos na agricultura minimizando, assim, o transporte e a permanência de moléculas diversas ao meio ambiente. ${ }^{3}$

As nanopartículas poliméricas são sistemas de liberação que alteram as propriedades físico-químicas de substâncias químicas, conforme sua aplicação. O avanço nos estudos desses sistemas é justificado pelas vantagens que os mesmos são capazes de desenvolver devido ao seu tamanho. A otimização de sistemas de liberação ocorre porque suas nano dimensões atingem alvos de difícil acesso e torna mais eficiente o contato com os mesmos, uma vez que a área de contato aumenta. Além disso, os sistemas de nanoestruturas têm uma importante característica de melhorar a velocidade da liberação e o regime de dosagem das substâncias..$^{5,6}$

Os sistemas de liberação contendo alginato e quitosana mostram-se promissores no encapsulamento de diferentes substâncias químicas, por exemplo, proteínas e peptídeos, fármacos, entre outros. A interação quitosana-alginato (CS-ALG) é formada através de um processo de gelificação ionotrópica via interações entre os grupos carboxílicos ionizados do alginato e os grupamentos amina ionizados do polímero quitosana. Destaca-se ainda que estes polímeros são biocompatíveis e biodegradáveis e, desta forma, são promissores para aplicações na produção de sistemas carreadores de compostos bioativos para o setor agrícola. ${ }^{7}$

Em trabalho prévio foi relatado o preparo e a caracterização físico-química de nanopartículas de alginato-quitosana contendo o herbicida clomazone. Além disso, nesse trabalho verificou-se a alteração de perfil de liberação do herbicida quando se encontra associado às nanopartículas. ${ }^{8}$ No presente estudo avaliou-se o perfil de sorção do clomazone (associado ou não às nanopartículas de alginato-quitosana) na presença de solos com diferentes características, a fim de se obter informações do mecanismo de sorção das nanopartículas. O estudo do mecanismo de sorção do clomazone nas suas formas livre e associado às nanopartículas abre perspectivas para o uso de nanopartículas em atividades agrícolas. Nos sistemas de liberação controlada, por exemplo, as nanopartículas poliméricas possuem diversos fatores positivos, entre eles, redução da quantidade de substância química necessária para o controle de pragas; diminuição do risco de contaminação ambiental; redução da quantidade de energia gasta (reduz o número de aplicações necessárias comparadas às formulações convencionais), aumento na segurança das pessoas responsáveis pela aplicação do produto no campo, entre outros.

\section{PARTE EXPERIMENTAL}

\section{Materiais}

O herbicida clomazone (2-[metil(2-clorofenil)]-4,4-dimetil3-isoxazolidinona)Pestanal ${ }^{\circledR}$ (Sigma Chem. Co, padrão analítico), quitosana, alginato (Sigma Chem. Co), água deionizada (sistema
Milli-Q (Millipore)), metanol (J.T. Baker) e todos os demais reagentes utilizados foram adquiridos em grau analítico. Membrana Millipore ${ }^{\circledR}$ de $0,22 \mu \mathrm{m}$, celulose regenerada de $30 \mathrm{kDa}$ (Microcon - Millipore ${ }^{\circledR}$ ), centrífuga e membrana de celulose (Spectrapore, com poro de exclusão molecular de $12000 \mathrm{Da}$ ).

\section{Métodos}

Metodologia analítica de quantificação do herbicida clomazone As condições cromatográficas utilizadas para a quantificação foram: fase móvel composta por metanol e água (60:40 v/v) em fluxo de $1 \mathrm{~mL} / \mathrm{min}$. O clomazone foi detectado em comprimento de onda de $220 \mathrm{~nm}$ utilizando-se um detector de ultravioleta (UV) e coluna Gemini RP-18 (150 mm x 4,60 mm, $5 \mu \mathrm{m}$, Phenomenex, Torrance, USA). O volume de injeção foi de $20 \mu \mathrm{L}$ e todas as amostras injetadas foram filtradas previamente em membrana de poli (éter-sulfona) de $0,22 \mu \mathrm{M}$ (Millipore ${ }^{\circledR}$ ). O clomazone total $(100 \%)$ presente na suspensão de nanopartículas de alginato foi determinado diluindo-se a suspensão em metanol. O metanol consegue dissolver o polímero, liberando totalmente o clomazone que, por sua vez, foi quantificado na curva analítica (faixa de concentração: $10-1500 \mu \mathrm{M}$, área do pico $=0,836 \times 10^{6}$ [clomazone $\left.-1,336 \times 10^{4}, \mathrm{r}=0,9996\right)$.

\section{Preparo das nanopartículas de alginato/quitosana (AG/QS)}

A preparação das nanopartículas de alginato de cálcio foi realizada segundo o método descrito por Sarmento et al..$^{9}$ Primeiramente, uma solução de alginato de sódio $(0,063 \%$ p/v) foi preparada e adicionaram-se lentamente $7,5 \mathrm{~mL}$ de solução de cloreto de cálcio (18 mM) durante 60 min, sob agitação mecânica. Posteriormente, 25 $\mathrm{mL}$ de solução de quitosana foram adicionados à primeira solução por um período de 90 min. Para o preparo da solução de quitosana foi utilizado ácido acético $(1 \mathrm{M})$ sob agitação durante um período de $12 \mathrm{~h}$. As nanopartículas foram armazenadas em frasco âmbar após o preparo, para posterior caracterização.

\section{Ensaios de sorção em solo}

A partir do estudo de várias metodologias empregadas em ensaio de sorção de herbicidas no solo, ${ }^{10,11}$ as condições foram adaptadas para os solos e o herbicida escolhidos por meio de um planejamento fatorial, variando-se quatro parâmetros em dois níveis: tipos de solo; quantidade de massa do solo; temperatura e forma em que se encontra o herbicida.

Os ensaios de sorção em solo foram realizados usando teste em equilíbrio padrão, com quantidade de herbicida ( $\mathrm{mg}$ por $\mathrm{L}$ de solução de $\left.\mathrm{CaCl}_{2} 0,01 \mathrm{M}, \mathrm{pH} 5,5\right)$. Uma alíquota de $20 \mathrm{~mL}$ contendo herbicida e solo foi colocada num erlenmeyer, sob agitação orbital $(100 \mathrm{rpm})$ à temperatura ambiente. Após $8 \mathrm{~h}$, foi retirado $1 \mathrm{~mL}$ de amostra, posteriormente centrifugado por $5 \mathrm{~min}$ a $2000 \mathrm{rpm}$. O sobrenadante foi então filtrado em filtro de $0,22 \mu \mathrm{m}$. A quantidade do herbicida no sobrenadante foi determinada por cromatografia líquida de alta eficiência (CLAE). Os experimentos de sorção em solo foram realizados com dois diferentes tipos de solo coletados na Amazônia, denominados de Iara e Carvoeiro 1, sendo suas características descritas na Tabela 1 . A sorção em equilíbrio foi calculada como a diferença de concentração entre a solução inicial e a solução em equilíbrio com o solo. ${ }^{12}$

\section{Otimização das condições de sorção: planejamento fatorial $2^{4}$}

Estudou-se, através de um planejamento fatorial $2^{4}$, a influência de quatro fatores no ensaio de sorção de herbicidas no solo: tipos de solo (diferenciado pela quantidade de matéria orgânica presente); quantidade de massa do solo; temperatura; forma como herbicida se encontra, em dois níveis, como apresentado nas Tabelas 2 e 3. 
Tabela 1. Características das amostras de solos da Bacia do Médio Rio Negro

\begin{tabular}{|c|c|c|}
\hline & Solo Iara & Solo Carvoeiro 1 \\
\hline Profundidade coleta $(\mathrm{cm})$ & $0-10$ & $0-10$ \\
\hline Classificação Pedológica & Solo gley húmico & Solo pdzólico vermelho amarelo \\
\hline Característica da região & $\begin{array}{l}\text { Proximidades do Lago Iara, região alagável } \\
\text { por rio de coloração escura }\end{array}$ & Mata da região de Carvoeiro, não alagáve \\
\hline Localização & S $01^{\circ} 20.010^{\prime \prime}$ & \\
\hline W $062^{\circ} 03.809^{\prime}$ & S $01^{\circ} 23.615^{\prime \prime}$ & \\
\hline \multicolumn{3}{|l|}{ W $061^{\circ} 58.776^{\prime \prime}$} \\
\hline $\mathrm{pH}$ & 3,4 & 3,1 \\
\hline Matéria orgânica (\%) & $24,66 \pm 0,30$ & $9,37 \pm 0,56$ \\
\hline $\mathrm{C} / \mathrm{N}$ & 16,0 & 18,3 \\
\hline Areia $(\%)$ & 39,8 & 54,0 \\
\hline Silte $(\%)$ & 40,10 & 34,6 \\
\hline Argila $(\%)$ & 20,10 & 11,4 \\
\hline
\end{tabular}

Tabela 2. Fatores variados em dois níveis no planejamento fatorial

\begin{tabular}{|c|c|c|c|c|}
\hline nível & $\begin{array}{l}\text { \% Matéria } \\
\text { orgânica }\end{array}$ & $\begin{array}{l}\text { Massa de } \\
\text { solo }\end{array}$ & $\begin{array}{c}\text { Temperatura } \\
\left({ }^{\circ} \mathrm{C}\right)\end{array}$ & Herbicida \\
\hline+ & $\begin{array}{c}24,66 \pm 0,30 \\
\text { (Solo Iara) }\end{array}$ & $1,6 \mathrm{~g}$ & 35 & Livre \\
\hline- & $\begin{array}{c}9,37 \pm 0,56 \text { (Solo } \\
\text { Carvoeiro } 1 \text { ) }\end{array}$ & $0,8 \mathrm{~g}$ & 25 & Nanopartículas \\
\hline
\end{tabular}

Tabela 3. Matriz experimental obtida pelo planejamento fatorial $2^{4}$ para estudo de sorção

\begin{tabular}{ccccc}
\hline Formulação & $\begin{array}{c}\text { Matéria } \\
\text { orgânica (A) }\end{array}$ & $\begin{array}{c}\text { Massa de solo } \\
(\mathrm{B})\end{array}$ & $\begin{array}{c}\text { Herbicida } \\
(\mathrm{C})\end{array}$ & $\begin{array}{c}\text { Temperatura } \\
(\mathrm{D})\end{array}$ \\
\hline 1 & - & - & + & - \\
2 & - & + & - & + \\
3 & + & + & + & + \\
4 & + & - & + & + \\
5 & + & - & - & - \\
6 & - & - & - & - \\
7 & + & - & - & + \\
8 & + & + & + & - \\
9 & + & - & + & - \\
10 & - & - & - & + \\
11 & - & + & - & - \\
12 & - & + & + & - \\
13 & - & + & + & + \\
14 & - & - & + & + \\
15 & + & + & - & - \\
16 & + & + & - & + \\
\hline
\end{tabular}

A partir do planejamento fatorial foram observados os fatores de resposta: concentração final de pesticida $\left(\mathrm{mg} \mathrm{L}^{-1}\right)$ após $8 \mathrm{~h}$ de ensaio de sorção e, a quantidade de pesticida, após $8 \mathrm{~h}$, por grama de solo.

A análise dos dados coletados no planejamento fatorial e os fatores de resposta foram analisados no software Statgraphics Plus versão 5.1. Os dados de saída da análise foram organizados em gráfico de Pareto e gráfico dos efeitos principais dos fatores.

\section{RESULTADOS E DISCUSSÃO}

\section{Estudo da sorção do herbicida clomazone em solos}

O ensaio de sorção foi realizado com o herbicida clomazone e, a partir dos dados coletados, foram construídas as curvas de cinéticas de sorção nas temperaturas de 25 e $35^{\circ} \mathrm{C}$.

A Figura 2 apresenta uma das isotermas de sorção obtidas para os ensaios do herbicida clomazone com o solo Iara à $25^{\circ} \mathrm{C}$.

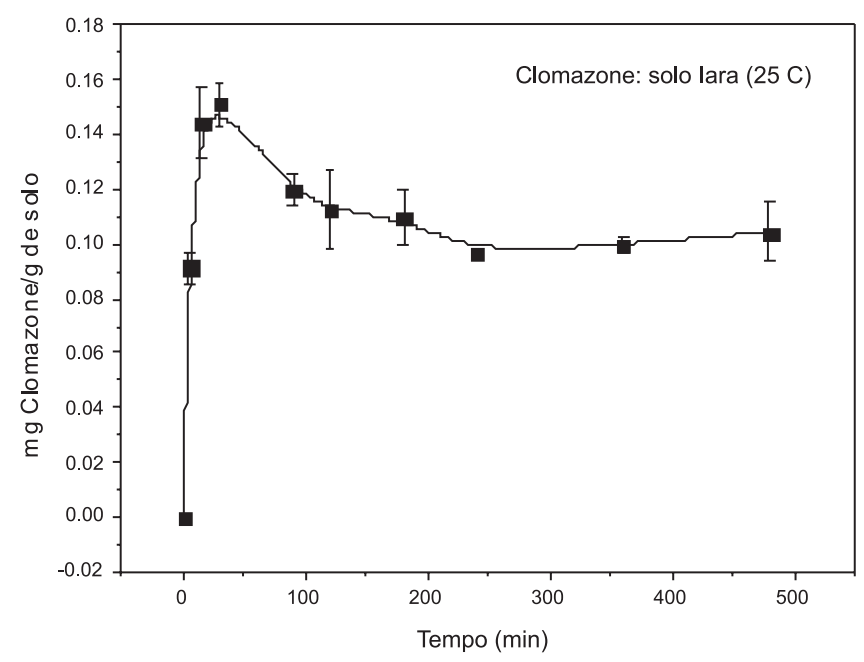

Figura 2. Curva de sorção do herbicida clomazone no solo Iara a $25{ }^{\circ} \mathrm{C}$ (pontos representam a média de três diferentes experimentos, $n=3$ )

A partir dos resultados mostrados na Figura 2, observa-se que o equilíbrio começa a ser estabelecido no tempo de $50 \mathrm{~min}$, quando se iniciam as competições moleculares entre os grupos funcionais do clomazone e os possíveis sítios ligantes da matéria orgânica e demais constituintes do solo (argila e silte). Este processo delonga-se até o tempo de aproximadamente $200 \mathrm{~min}$, mantendo-se praticamente estável até $480 \mathrm{~min}$. Este comportamento geralmente é observado em estudos de adsorção/complexação, tanto de compostos orgânicos como inorgânicos, nas interações com o solo/matéria orgânica natural. Desta forma, foi definido o tempo de $480 \mathrm{~min}$ a fim de garantir que o sistema realmente atingiu o equilíbrio, permitindo a obtenção das isotermas de adsorção do clomazone no solo Iara.

A fim de obter maiores informações sobre o mecanismo de sorção 
deste herbicida nos diferentes solos, foi utilizado modelo matemático de pseudossegunda ordem (Equação 1) para análise do perfil de sorção. Este modelo tem como base a capacidade de sorção no equilíbrio, e considera a sorção química entre o sólido sorvente e o soluto presente na fase líquida, através de troca e/ou compartilhamento de elétrons entre a fase líquida e o material sólido. ${ }^{13} \mathrm{~A}$ lei de velocidade para segunda ordem pode ser expressa pela Equação linearizada 1.

$$
\frac{t}{q t}=\frac{1}{\left(k 2 * q e^{2}\right)}+\frac{t}{q e}
$$

onde qe é quantidade de soluto ou substância química adsorvida no equilíbrio $\left(\mu \mathrm{mol} \mathrm{g}^{-1}\right)$; qt: quantidade de soluto/substância química adsorvida no tempo $\mathrm{t}\left(\mu \mathrm{mol} \mathrm{g}{ }^{-1}\right) ; \mathrm{k} 2$ : constante de velocidade $\left(\mathrm{g} \mu \mathrm{mol}^{-1}\right.$ $\left.\min ^{-1}\right)$; t: tempo em min.

A constante de velocidade $(k 2)$ de pseudossegunda ordem e qe podem ser obtidas a partir do gráfico t/qt versus $t$. Portanto, o parâmetro que interfere na cinética de sorção é a capacidade de sorção no equilíbrio qe, que depende da concentração inicial, da natureza do soluto e, também, da qualidade do sorvente.

A equação de pseudossegunda ordem não exige o conhecimento prévio da capacidade de sorção no equilíbrio. Além disso, esse parâmetro permite, bem como a constante e velocidade de pseudossegunda ordem, que a velocidade inicial da sorção possa ser determinada a partir da equação sem o conhecimento anterior de qualquer anterior de qualquer outro parâmetro. ${ }^{13,14}$

Os resultados obtidos a partir dos ajustes das curvas cinéticas do herbicida clomazone nos diferentes solos estão apresentados na Figura 3 e Tabela 4.

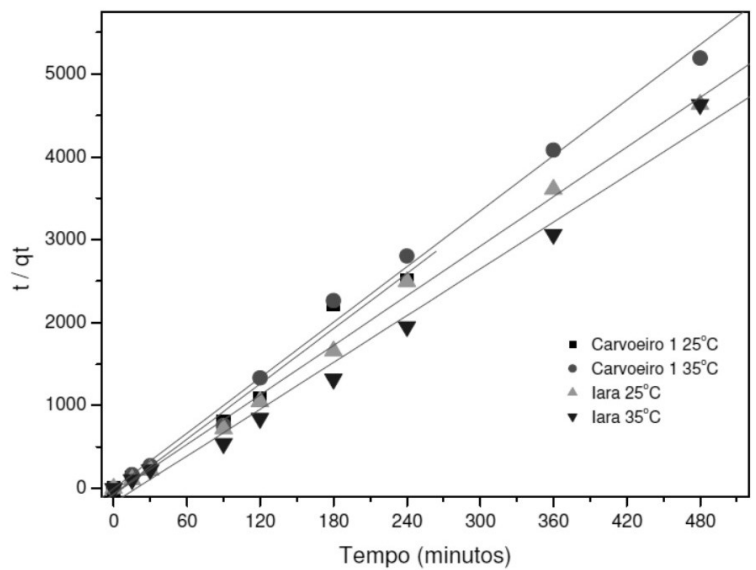

Figura 3. Modelo cinético de pseudossegunda ordem aplicado às isotermas de sorção do herbicida clomazone nos solos Carvoeiro 1 e Iara em duas diferentes temperaturas $\left(25\right.$ e $35^{\circ} \mathrm{C}$ ) (pontos representam a média de três diferentes experimentos, $n=3$ )

O modelo cinético de pseudossegunda ordem, Figura 3, pode ser usado para descrever o mecanismo de sorção do herbicida clomazone, pois é capaz de descrever sorção em superfícies heterogêneas sem conhecimento prévio da capacidade de sorção no equilíbrio.

A equação de pseudossegunda ordem pode ser usada em casos em que a capacidade de adsorção no equilíbrio é desconhecida; a quimissorção tende a tornar-se imensurável e a quantidade adsorvida é ainda insignificante em relação à quantidade no equilíbrio, como pôde ser verificado no ensaio de sorção do herbicida clomazone. Portanto, o modelo de pseudossegunda ordem possui algumas vantagens: não tem o problema da atribuição de uma eficaz capacidade de adsorção, ou seja, a capacidade de adsorção, a constante de velocidade, a velocidade inicial de sorção, todas estas variáveis podem ser determinadas a partir da equação de pseudossegunda ordem, sem se conhecer de antemão qualquer parâmetro. ${ }^{15}$

Nota-se a partir da Tabela 4 que os coeficientes de correlação linear $\left(r^{2}\right)$ encontrados para os quatro experimentos ficaram bem próximos ao valor 1, demonstrando, assim, bom ajuste linear de cada situação ao modelo de pseudossegunda ordem.

Os valores encontrados para capacidade de sorção do equilíbrio $q e$, no tempo de $8 \mathrm{~h}$, não variaram significativamente de um solo para outro.

Observa-se, entretanto, que no solo Iara, com maior teor de matéria orgânica, à temperatura de $25^{\circ} \mathrm{C}$ a taxa inicial de adsorção de clomazone $(h)$ é maior do que à $35^{\circ} \mathrm{C}$. O mesmo comportamento é observado para $k 2$ referente à constante de velocidade de remoção do herbicida do solo.

O processo de sorção na presença do solo Carvoeiro 1, com menor porcentagem de matéria orgânica, à temperatura de $35^{\circ} \mathrm{C}$ apresenta maiores constante de velocidade de sorção e taxa inicial de adsorção.

No geral, observa-se uma proximidade entre os dados obtidos para a variável qe nos quatro ensaios cinéticos. Porém, a constante de velocidade de sorção e a taxa inicial de adsorção de clomazone mostram depender dos parâmetros temperatura e quantidade de matéria orgânica no solo de maneira hipoteticamente combinada, de modo que não é possível inferir, apenas com os dados presentes, a forma como essas duas variáveis se correlacionam.

As características físico-químicas no clomazone, tais como alta solubilidade em água e demorada degradação no meio ambiente por meio de processos como fotólise e hidrólise (ainda que em diferentes $\mathrm{pH}$ ), tornam importante o conhecimento de seu mecanismo no solo. Poucos são os trabalhos científicos que caracterizam a sorção do clomazone em solos, e menos ainda são os trabalhos voltados para entender a atuação deste herbicida em áreas alagadas de cultivo de arroz e suas consequências. Estudos mostram que, apesar do herbicida clomazone ter uma tendência de baixa sorção em solos, o herbicida apresenta baixa dessorção em solos com presença de ácido húmico. ${ }^{16}$

Os coeficientes Koc e Kow do herbicida clomazone (Koc: 150-562 $\mathrm{cm}^{3} \mathrm{~g}^{-1}$ e log Kow: 2,54) também podem ser usados para compreender sua atividade no solo. ${ }^{17}$

O coeficiente de partição octanol-água, Kow, refere-se ao grau de afinidade da molécula de pesticida pela fase polar (representada pela água) ou apolar (representada pela substância 1-octanol), podendo ser determinado pela Equação 2.

$$
\text { Kow }=\frac{C_{\text {octanol }}}{C_{\text {agua }}}
$$

$C_{\text {octanol }}$ e $C_{\text {ăgua }}$ correspondem à concentração do herbicida no equilíbrio no octanol e água, respectivamente. Portanto, quanto maior

Tabela 4. Resultado dos valores de cinética de pseudossegunda ordem obtidos das análises das curvas cinéticas de sorção do herbicida clomazone nos diferentes solos (Iara e Carvoeiro 1) em duas diferentes temperaturas

\begin{tabular}{lcccccccc}
\hline & \multicolumn{3}{c}{ Solo Iara } & \multicolumn{3}{c}{ Solo Carvoeiro 1 } \\
\cline { 2 - 8 } & $Q e\left(\mathrm{mg} \mathrm{g}^{-1}\right)$ & $k 2\left(\mathrm{~g} \mathrm{mg}^{-1} \mathrm{~min}^{-1}\right)$ & $h\left(\mathrm{mg} \mathrm{g}^{-1} \mathrm{~min}^{-1}\right)$ & $R^{2}$ & $q e\left(\mathrm{mg} \mathrm{g}^{-1}\right)$ & $k 2\left(\mathrm{~g} \mathrm{mg}^{-1} \mathrm{~min}^{-1}\right)$ & $h\left(\mathrm{mg} \mathrm{g}^{-1} \mathrm{~min}^{-1}\right)$ & $R^{2}$ \\
\hline $25^{\circ} \mathrm{C}$ & 0,09632 & $1,74 \times 10^{12}$ & $1,61 \times 10^{10}$ & 0,999 & 0,09583 & $1,16 \times 10^{5}$ & $1,07 \times 10^{6}$ & 0,999 \\
$35^{\circ} \mathrm{C}$ & 0,16469 & $2,64 \times 10^{11}$ & $7,15 \times 10^{6}$ & 0,998 & 0,09912 & $2,45 \times 10^{13}$ & $2,41 \times 10^{11}$ & 0,987 \\
\hline
\end{tabular}


o Kow de uma substância, maior a sua capacidade de se dissolver no solvente orgânico, trata-se de uma medida de lipofilicidade e, portanto, também da afinidade com a matéria orgânica do solo. Esta propriedade pode ser usada para avaliar a atividade de herbicidas na solução do solo, ou seja, o quanto da molécula de herbicida está livre em água ou associada às substâncias orgânicas. ${ }^{18}$

$\mathrm{O}$ coeficiente de adsorção à matéria orgânica do solo, denominado $K o c$, reflete a tendência de adsorção do herbicida pelo carbono orgânico do solo. Alguns autores apontam ainda certa relação entre os coeficientes Kow e Koc. Quanto menor for o valor de Kow, maior será o potencial de lixiviação do herbicida. Por sua vez, quanto maior for o valor de Koc, maior será sua sorção ao solo. ${ }^{18}$

O herbicida clomazone apresenta baixo valor de Kow, tendo como referência o valor descrito na literatura, o que justifica sua maior tendência a sofrer lixiviação em presença de água, devido também ao fato de ser muito solúvel em água (1100 $\left.\mathrm{mg} \mathrm{L}^{-1}\right)$, e menor afinidade à matéria orgânica presente no solo. Assim também, o baixo valor de Koc do clomazone comprova a sua baixa afinidade com a matéria orgânica presente no solo.

\section{Otimização das condições de sorção: planejamento fatorial $2^{4}$}

A fim de estudar as variáveis envolvidas no processo de sorção do herbicida clomazone na forma livre e na forma associada às nanopartículas de alginato/quitosana foi realizado um planejamento fatorial $2^{4}$, conforme descrito na Tabelas 2 e 3.

As nanopartículas de alginato/quitosana contendo o herbicida clomazone apresentaram valores: potencial zeta de $-7,5 \mathrm{mV}$, diâmetro médio hidrodinâmico (distribuição do diâmetro médio das partículas e das moléculas de água ao seu redor medido por espectroscopia de correlação de fótons utilizando-se um analisador de partículas Zetasizer Nano ZS90, Malvern) de $633 \mathrm{~nm}$ e um valor de $\mathrm{pH}$ da suspensão de 4,72. Os resultados encontrados são compatíveis com os dados descritos na literatura para a metodologia de preparo utilizada. ${ }^{9,19} \mathrm{O}$ herbicida apresentou taxa de associação de $59,1 \%$ para a formulação de nanopartículas alginato/quitosana. A taxa de associação pode ter sido influenciada por diversos fatores como, por exemplo, concentração de cloreto de cálcio, alginato de sódio e de quitosana utilizado nas preparações das nanopartículas. ${ }^{8}$

Os dados do planejamento fatorial foram analisados pelo software Statgraphics Plus versão 5.1, sendo os resultados obtidos apresentados nas Tabela 5 e Figuras 4 e 5.

Tabela 5. Estimativa dos efeitos e valores de $p$ para variação da sorção de clomazone por massa de solo. Variáveis A: matéria orgânica; B: quantidade de solo; C: forma do herbicida; D: temperatura, como descritas inicialmente no planejamento fatorial

\begin{tabular}{lcc}
\hline Fatores variados & Estimativa dos efeitos & $P$ \\
\hline C: Forma do pesticida & $+10,6$ & 0,001 \\
A: Matéria orgânica & $+3,8$ & 0,006 \\
B: Quantidade de solo & $+3,1$ & 0,039 \\
\hline
\end{tabular}

As Figuras 4 e 5 indicam que a forma como se encontra o herbicida clomazone, ou seja, livre (sem se associar às partículas) ou incorporado às nanopartículas de alginato/quitosana, é o principal parâmetro que influencia na quantidade de pesticida adsorvido no solo (miligrama por grama de solo), assim como na concentração final no líquido sobrenadante do ensaio de sorção. Os outros dois parâmetros que apresentaram efeitos na sorção do herbicida foram o tipo de solo (ou quantidade de matéria orgânica) e a quantidade de solo.

O uso de planejamento experimental foi importante para avaliação dos parâmetros no estudo das nanopartículas no solo, uma vez que este
Gráfico de Pareto - Quantidade de sorção

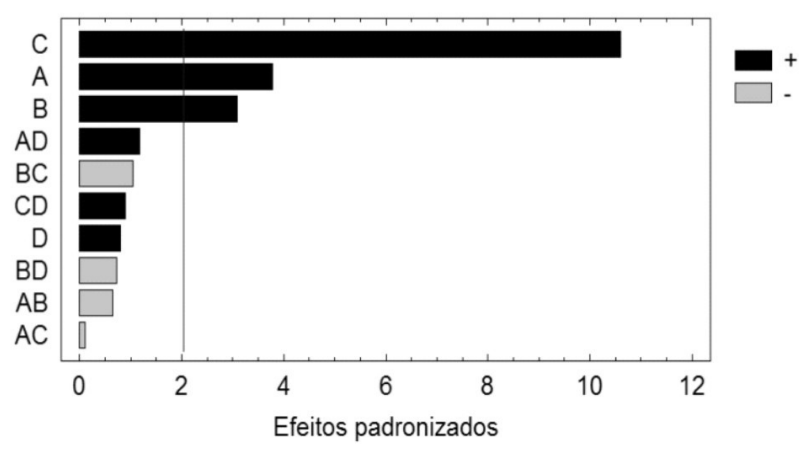

Gráfico de Pareto - Concentração final

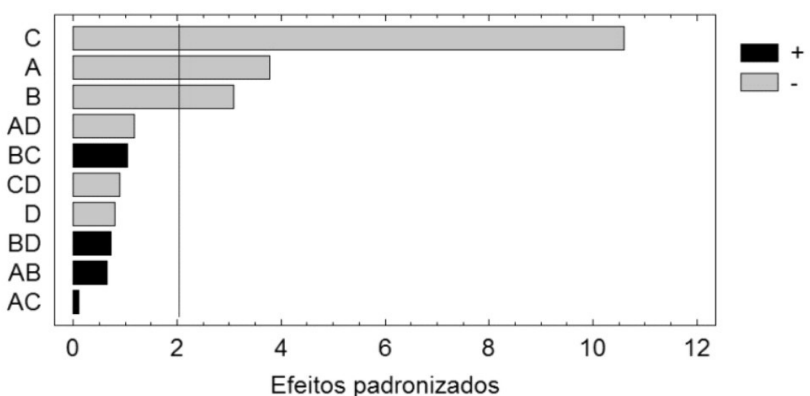

Figura 4. Gráficos de Pareto levando em consideração as respostas, após $8 \mathrm{~h}$ de ensaios (tempo final). Os resultados foram analisados em função da quantidade de sorção de clomazone por massa de solo e concentração final de clomazone no sobrenadante. Variáveis A: matéria orgânica; B: quantidade de solo; C: forma do herbicida; D: temperatura, como descritas inicialmente no planejamento fatorial
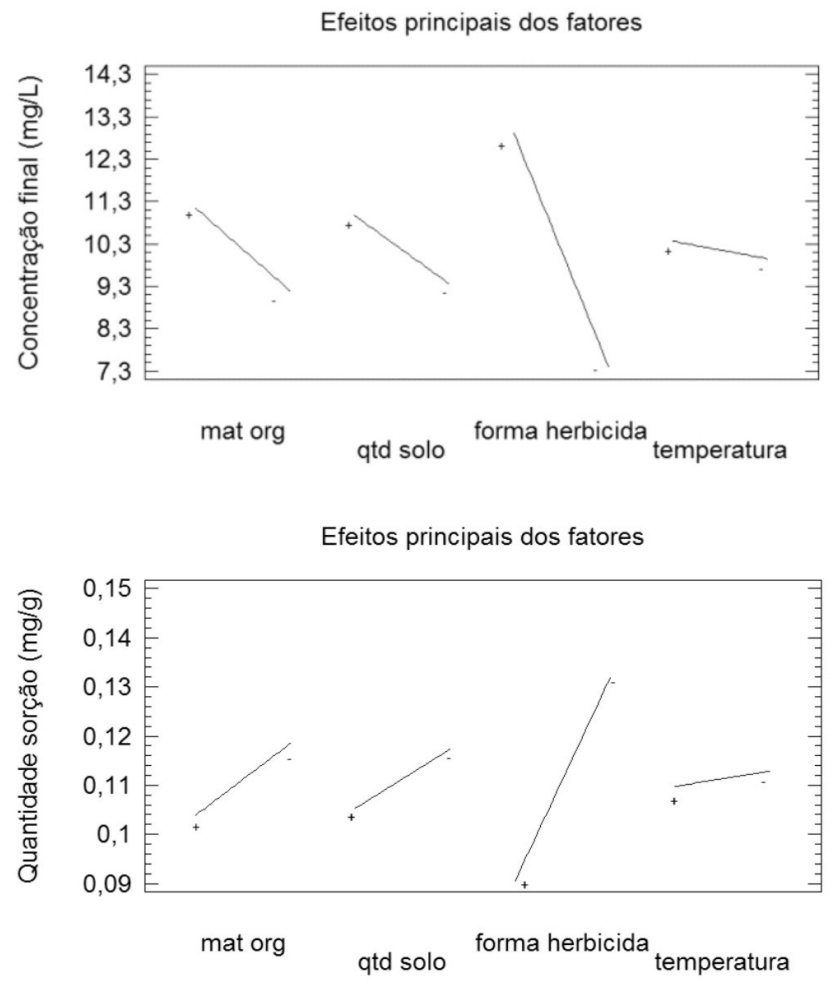

Figura 5. Gráficos de efeitos principais dos fatores levando em consideração as respostas, após $8 \mathrm{~h}$. Os resultados foram analisados em função da quantidade de sorção de clomazone por massa de solo e concentração final de clomazone no sobrenadante 
novo sistema proposto de liberação de agroquímicos pode diminuir os impactos ambientais melhorando a quantidade de produto a ser aplicada, fazendo com que os pesticidas atinjam o alvo desejado, uma vez que devido à baixa sorção no solo (pelo fato do herbicida estar associado) não ficam retidos ao solo (e à matéria orgânica presente no solo), melhorando assim a sua disponibilidade para ação herbicida. ${ }^{20,21}$

\section{CONCLUSÃO}

Os resultados obtidos forneceram informações importantes sobre a aplicação de nanopartículas de alginato/quitosana como sistema carreador para o herbicida clomazone. Além de complementar os dados publicados previamente, ${ }^{8}$ os ensaios de sorção aplicados para o herbicida clomazone nas formas livre e associado às nanopartículas alginato/quitosana permitiram avaliar a alteração no perfil de sorção quando o herbicida se encontra associado às nanopartículas. Portanto, as nanopartículas poliméricas podem se tornar uma importante alternativa no desenvolvimento de novas tecnologias aplicadas à atividade agrícola. O uso de nanopartículas poliméricas como sistema de liberação de herbicidas mostrou ser uma importante ferramenta de estudo no controle de plantas daninhas, porque este sistema é capaz de reduzir as aplicações em culturas, diminuindo assim custos e energia gasta. Além disso, as nanopartículas são capazes de aumentar o tempo de atuação de agroquímicos e fazem com que os princípios ativos atinjam os organismos alvos de interesse, evitando que estas substâncias químicas se acumulem em matrizes ambientais.

\section{AGRADECIMENTOS}

À FAPESP, ao CNPq e Fundunesp pelos auxílios financeiros.

\section{REFERENCIAS}

1. Zanella, R; Primel, E. G.; Gonçalves, F. F.; Martins, M. L.; Adaime, M. B.; Marchesanc, E.; Machadoc, S. L. O.; J. Braz. Chem. Soc. 2008, 19, 5 .
2. Miron, D. D. S.; Tese de Doutorado. Universidade Federal de Santa Maria, Brasil, 2009.

3. Estévez, M. A.; Periago, E. L.; Carballo, E. M.; Gándara, J. S.; Mejuto, J. C.; Río, L. G.; Agriculture, Ecosystems and Environment 2008, 123, 247.

4. Gevao, B.; Semple, K. T.; Environ. Pollut. 2000, 108, 3.

5. Letchford, K.; Burt, H.; Eur. J. Pharm. Biopharm. 2007, 65, 259.

6. Schaffazick, S. R.; Guterres, S. S.; Freitas, L. L.; Pohlmann, A. R.; Quim. Nova 2003, 26, 726.

7. Motwani, S. K.; Chopra, S.; Talegaonkar, S.; Kohli, K.; Ahmad, F. J.; Khar, R. K.; Eur. J. Pharm. Biopharm. 2008, 68, 513.

8. Silva, M. D. S.; Cocenza, D. S.; Melo, N. F. S.; Grillo, R.; Rosa, A. H.; Fraceto, L. F.; Quim. Nova 2010, 33, 9.

9. Sarmento, B.; Ferreira, D.; Veiga, F.; Ribeiro, A.; Carbohydr. Polym. 2006, 66, 1.

10. Oliveira, V. S.; Lima, J. M.; Carvalho, R. F.; Quim. Nova 2009, 32, 6.

11. Weber, O. L. S.; Martins, E. L.; Dores, E. F. G. C.; Curado, L. D. A.; Quim. Nova 2009, 32, 2259.

12. Villaverde, J.; Maqueda, C.; Morillo, E.; J. Agric. Food Chem. 2006, 54, 10192.

13. Oliveira, E. A.; Tese de pós-graduação, Universidade Estadual de Maringá, Brasil, 2007.

14. Qin, F.; Wen, B.; Shan, X. Q.; Xie, Y. N.; Liu, T.; Zhang, S. Z.; Khan, S. U.; Environ. Pollut. 2006, 144, 669.

15. Ho, Y.S.; Mckay, G.; Process Biochem. 1999, 34, 451.

16. Wen-Tien, T.; Chi-Wei, L.; J. Hazard. Mater. 2006, 134, 144.

17. Gonçalves, F. F.; Tese de Doutorado, Universidade Federal de Santa Maria, Brasil, 2007.

18. Passos, A. T. M.; Dissertação de Mestrado, Universidade do Oeste Paulista, Brasil, 2007.

19. Chavanpatil, M. D.; Khdair, A.; Patil, Y.; Handa, H.; Mao, G.; Panyam, J.; J. Pharm. Sci. 2007, 96, 3379.

20. Tsai, W. T.; Lai, C. W.; Hsien, K. J.; J. Colloid Interface Sci. 2003, 263, 29.

21. Spark, K. M.; Swift, R. S.; Sci. Total Environ. 2002, 298, 147. 